\title{
A Pharmacological Review on Portulaca oleracea L.: Focusing on Anti-Inflammatory, Anti- Oxidant, Immuno-Modulatory and Antitumor Activities
}

\author{
Vafa Baradaran Rahimi ${ }^{1,2+}$, Farideh Ajam ${ }^{2 \dagger}$, Hasan Rakhshandeh², Vahid Reza Askari' ${ }^{2,3 *}$ \\ 1 Student Research Committee, Department of Pharmacology, Faculty of Medicine, Mashhad University of Medical Sciences, Mashhad, Iran \\ ${ }^{2}$ Pharmacological Research Center of Medicinal Plants, Mashhad University of Medical Sciences, Mashhad, Iran \\ ${ }^{3}$ Neurogenic Inflammation Research Center, Mashhad University of Medical Sciences, Mashhad, Iran
}

\section{Key Words}

purslane, immuno-modulation, inflammation, Portulaca oleracea

\begin{abstract}
Portulaca oleracea L. (PO) or Purslane is an annual grassy plant that is distributed in many parts of the world, especially the tropical and subtropical areas. PO has some pharmacological properties such as analgesic, antibacterial, skeletal muscle-relaxant, wound-healing, anti- inflammatory and a radical scavenger. This review article is focused on the anti-inflammatory, immuno-modulatory, anti-oxidant and anti-tumor activities of the PO. Anti-inflammatory, immuno-modulatory, anti-oxidant and Anti-tumor effects of PO were searched using various databases until the end of $\mathrm{Au}$ gust 2018. The online literature was searched using $\mathrm{Pu}$ bMed, Science Direct, Scopus, Google Scholar and Web of Science. Our review showed that PO exerts its effects through anti-inflammatory properties and balancing the adaptive and innate immune system depending on situations. $\mathrm{PO}$ acts as immune-modulator and anti-oxidant agent in both inflammatory states by the dominance of Th2 response such as asthma, cancer and atopic dermatitis and evoked Thl disorders including hepatitis and multiple sclerosis.
\end{abstract}

Received: Aug 07, 2018 Reviewed: Oct 27, 2018 Accepted: Feb 11, 2019

(c) This is an Open-Access article distributed under the terms of the Creative Common Attribution Non-Commercial License (http://creativecommons.org/licenses/by-nc/4.0/) which permits unrestricted noncommercial use, distribution, and reproduction in any medium, provided the original work is properly cited.

(2) This paper meets the requirements of KS X ISO 9706, ISO 9706-1994 and ANSI/NISO Z39.48-1992 (Permanence of Paper)

\section{Introduction}

Portulacaceae comprises 25-30 genera and between 450-500 species that Portulaca is the largest genus in this family [1]. Portulaca oleracea L.(PO) is an annual grassy [2] plant with a fleshy stem, succulent leaves, yellow or white small flowers and small black seeds. It is distributed in many parts of the world and especially the tropical and subtropical areas. Purslane has been widely used as a potherb in the Mediterranean, central European and Asian countries [4] and has been given the term Global Panacea [5]. Purslane is classified as a C4 plant, which is listed as one of the most useful medicinal plants [6]. It is used as a herbal medicine in many countries, acting as a diuretic, febrifuge, vermifuge, antiseptic, anti-spasmodic and has pharmacological activities including analgesic, anti-bacterial, skeletal muscle-relaxant, wound- healing [7], anti-inflammatory [8], radical scavenger [2] and anti-convulsant [9]. Furthermore, it has been used for mitigating a wide range of diseases including gastrointestinal diseases, respiratory disorders, liver inflammation, kidney and bladder ulcers, fevers, insomnia, inflammations and headaches [4]. Moreover, PO is known to regulate the lipid and sugar metabolism in the body [6]. The stems and leaves of the purslane are edible and have a taste similar to spinach. The aerial parts of this plant in medicine are used to reduce pain and swelling as well as an antiseptic. In China, the dried plant can be boiled and used to prepare tea or soup. The aqueous extract of this plant did not show any cytotoxicity or genotoxicity. For this reason, the purslane plant is

$\dagger$ The authors had equal contributions as the first author. 
considered a safe daily vegetable. The methanolic extract of this plant had shown anti-microbial activity against $B a$ cillus subtilis [10].

PO is a plant with good nutritional and medicinal potentials that can be used as animal feed and food processing industry [11]. It has been demonstrated that about $10 \%$ of PO ethanolic extract had anti-inflammatory and analgesic activity in comparison with synthetic drugs [12]. The leaves and seeds of purslane can be used orally or applied topically to mitigate skin allergy [13].

In this study, we aimed to review the anti-inflammatory, anti-oxidant, immune-modulatory and anti-tumor properties of PO.

\section{Materials Methods}

The online literature was searched using PubMed, Science Direct, Scopus, Google Scholar and Web of Science. Anti-inflammatory, Immuno-modulatory, Anti-oxidant and Anti-tumor effects of PO were searched using various databases until the end of August 2018. The following keywords were used for the current study: anti-inflammatory, anti-oxidant, anti-tumor, immuno- modulatory, inflammation, oxidative stress, different scientific, common name of Portulaca oleracea and Purslane, respectively.

\subsection{Phytochemistry}

Previous studies have shown that PO possess many bioactive compounds such as flavonoids, coumarins, monoterpene glycoside [12], phenolic compounds [14], fatty acids as well as alpha- linolenic acid (Omega-3), alkaloids [2], vitamins, minerals and some other compound [15] which are listed in figure 1 .

Flavonoids are one of the most abundant and important active constituents of PO. Kaempferol and apigenin have been mainly isolated from leaf and stem [16]. Also, Luteolin, myricetin, quercetin [16], genistein and genistin [17] have been derived from the whole plant. Portulacanones A, portulacanones $\mathrm{B}$, portulacanones $\mathrm{C}$, portulacanones D and 2,2'-Dihydroxy- 4',6'-dimethoxychalcone have been isolated from aerial parts of PO [18].

Several alkaloids have been isolated from different parts of PO. Dopamine [19], noradrenalin [20] and DOPA are major alkaloids found in stem, leaf and seeds of PO [21]. Oleraceins A, oleraceins B, oleraceins C, oleraceins D, oleraceins $\mathrm{E}$ and adenosine have been derived from whole plant and oleracins I and oleracins II mainly found in PO stem [21]. Other alkaloids have been insulated from aerial parts of PO including $\mathrm{N}$-trans-Feruloyltyramine, (7'R)-N-Feruloylnormetanephrine, 1,5-Dimethyl-6-phe-

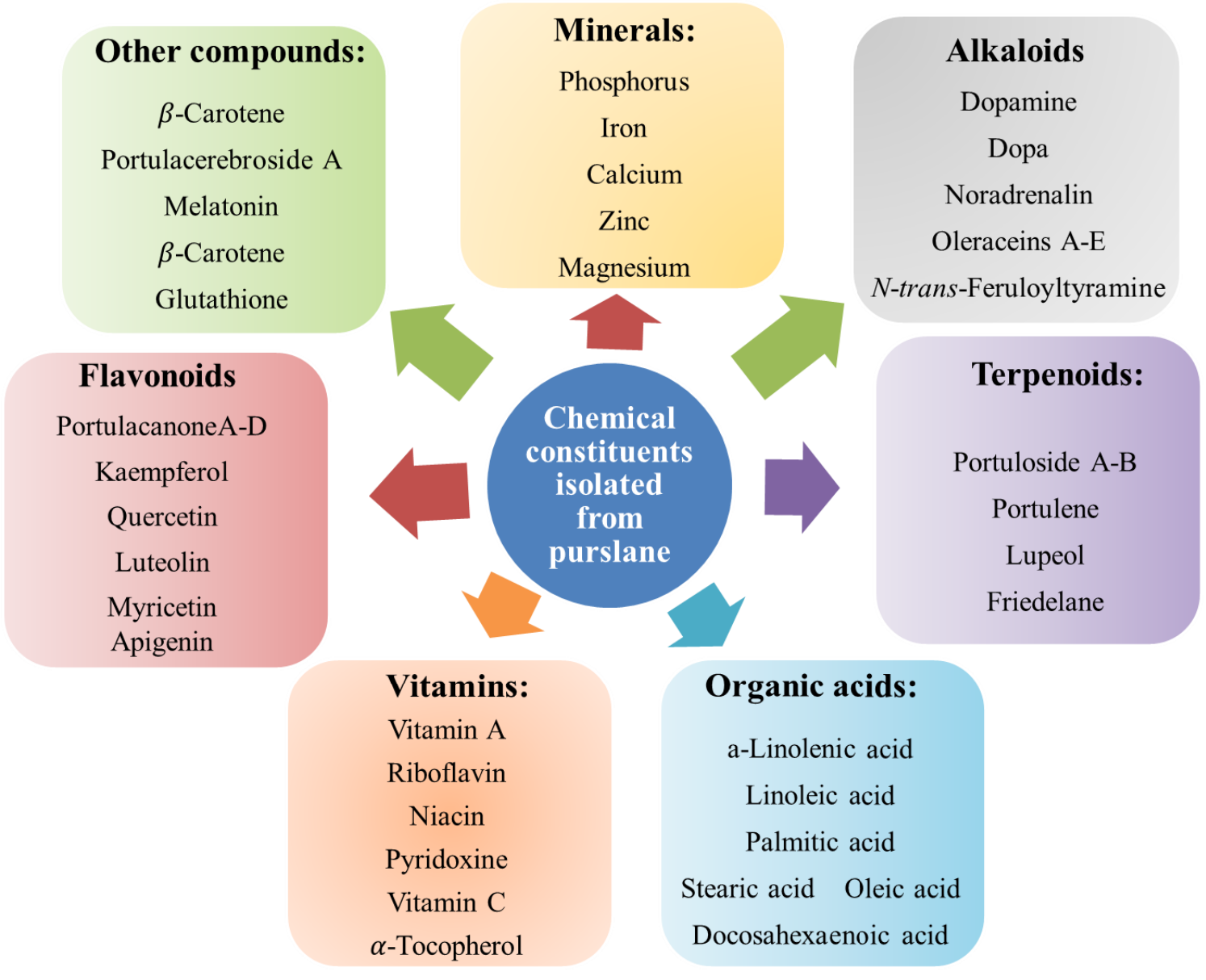

Figure 1 Chemical Constituents of PO 
nyl-1,2-dihydro-1,2,4-triazin-3(2H)-one, (3R)-3,5-Bis(3methoxy-4-hydroxyphenyl)-2,3-dihydro-2(1H)-pyridinone [22], Thymine,Uracil, N-cis-Feruloyltyramine, $\mathrm{N}$-trans-Feruloyloctopamine, N-cis-Feruloyloctopamine [18], Trollisine, Aurantiamide, Aurantiamide acetate, Cyclo (L-tyrosinyl-L-tyrosinyl),1,5-Dimethyl-6-phenyl-1, 6, 3, 4-tetrahydro-1,2,4-2(1H)-triazin [23] and Scopoletin [24].

Different terpenoids have been isolated from aerial parts of PO such as Portuloside A [25], Portuloside B, (3S)-3-O O-( $\beta$-D-Glucopyranosyl)-3,7-dimethylocta-1,6-dien-3-ol (34), (3S)-3-O-( $\beta$-D-Glucopyranosyl)-3,7-dimethylocta-1, 5-dien-3,7-diol (35) [26], Portulene, Lupeol [27], (2a,3a)-2, 23 , 30-Trihydroxy-3-[( $\beta$-D-xylopyranosyl)oxy]olean-12-en28-oic acid and Friedelane [28].

It has been demonstrated that PO possesses several minerals such as phosphorus, iron, manganese, calcium and copper in root, stem and leaf [29] and zinc, selenium and magnesium in its leaf [30].

Furthermore, various vitamins have been found in PO leaf including vitamin $\mathrm{A}$, riboflavin, niacin, pyridoxine, vitamin C, folates, pantothenic acid and thiamin [30] as well as hesperidin [31] and $\alpha$-tocopherol [32].

Omega-3 fatty acids pertain to polyunsaturated fatty acids that could not be synthesized by human bodies. Therefore, they should be utilized from dietary sources. Fish is considered the richest source of omega-3 fatty acids with high cholesterol. However, it has been revealed that PO is the richest vegetable origin of essential omega- 3 fatty acids with no cholesterol, especially alpha-linolenic acid (ALA) [30]. Different fatty acids have been isolated from PO such as 3-Quinolinecarboxylic acid, Indole-3-carboxylic acid [18] and caffeic acid in aerial parts, docosapentaenoic acid [30], eicosapentaenoic acid, docosahexaenoic acid and catechol in stem [33]. Furthermore, it possesses a-Linolenic acid [34], linoleic acid [30], palmitic acid, stearic acid, oleic acid [32] and oxalic acid [35] in leaf as well as p-Coumaric acid and ferulic acid in whole plant [21].

Furthermore, PO contains acidic pectic polysaccharides, neutral arabino galactan, arabinoglucomannans and starch [36]. It has been reported that polysaccharides isolated from PO show different biological activities, such as anti-cancer, anti-oxidant, anti-inflammatory and immunity enhancing properties [15].

\subsection{Anti-Inflammatory Activity}

Inflammation is known as one of the protective effects against harmful stimuli. If this condition becomes chronic, inflammation by own causes the cell and tissues injuries. Two alkaloids isolated from the PO, oleracone and oleracimine, have revealed significant anti-inflammatory effects on LPS-stimulated macrophages. These compounds remarkably prevent nitric oxide (NO) production. Moreover, they significantly diminished the secretion of interleukin 6 (IL-6), tumor necrosis factor $\alpha$ (TNF- $\alpha$ ), NO and prostaglandin E2 as well as mRNA cyclooxygenase 2 and inducible nitric oxide synthase [37]. Kim et al suggested that mRNA expression of the inflammatory factors including TNF- $\alpha$ and IL- $1 \beta$ is suppressed by PO in a dose-dependent manner, while the expression of COX-2 remained unchanged in LPS-stimulated AGS gastric cancer cells [38].

Lee et al indicated that pretreatment with the PO aqueous extract has an important role in suppression of TNFa-induced intracellular reactive oxygen species (ROS) over-production, overexpression of intercellular adhesion molecule-1 (ICAM-1), vascular cell adhesion molecule- 1 (VCAM-1) and E-selectin in human umbilical vein endothelial cells (HUVECs) in a concentration-dependent manner. Moreover, it prevented the adhesion of HL-60 cells to TNF- $\alpha$ - induced HUVECs and TNF- $\alpha$-induced mRNA expression of IL-8 and monocyte chemoattractant protein-1 (MCP-1). Moreover, aqueous extract of PO inhibited the translocation of NF-KB to the nucleus and NF-KB binding in HUVEC cells. In conclusion, it has been demonstrated that aqueous extract of PO possesses anti-vascular inflammatory effects and it could be effective in the prevention and treatment of vascular inflammatory diseases [7].

Hypoxia is related to many physiological and pathological cases such as pulmonary diseases. It can enhance the ROS production in mitochondria, which is the major

Table 1 Summary of the anti-inflammatory effects of Portulaca oleracea.

\begin{tabular}{|c|c|c|c|}
\hline $\begin{array}{c}\text { Type of extract or } \\
\text { constituents }\end{array}$ & Study model & Result & Ref. \\
\hline Oleracone and oleracimine & LPS-stimulated macrophages & $\begin{array}{l}\text { Diminished the secretion of IL- } 6, \mathrm{TNF}-\alpha, \mathrm{NO}, \\
\text { prostaglandin E2, mRNA cyclooxygenase } 2 \text { and } \\
\text { inducible nitric oxide synthase }\end{array}$ & 37 \\
\hline $\begin{array}{c}90 \% \text { ethanolic macerated PO } \\
\text { extract }\end{array}$ & $\begin{array}{l}\text { LPS-stimulated AGS gastric } \\
\text { cancer cells }\end{array}$ & Decreased TNF- $\alpha$ and IL- $1 \beta$ mRNA expression & 38 \\
\hline PO aqueous extract & HUVECs cells & 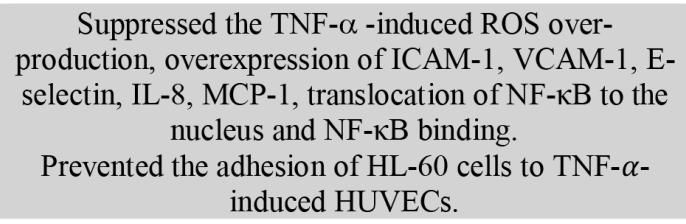 & 7 \\
\hline PO $80 \%$ ethanolic extract & $\begin{array}{l}\text { hypoxia-induced pulmonary } \\
\text { edema in mouse }\end{array}$ & $\begin{array}{l}\text { Reduced the vascular permeability, NF- } \kappa \text { B up- } \\
\text { regulation, the levels of IL-1 } \beta \text {, TNF- } \alpha \text {, ICAM-1, } \\
\text { VCAM-1, and P-selectin }\end{array}$ & 12 \\
\hline CPOP & $\begin{array}{l}\text { Streptozotocin-induced } \\
\text { diabetes in the rat }\end{array}$ & Alleviated TNF- $\alpha$, IL-6, SOD and MDA levels & 6 \\
\hline
\end{tabular}


material of oxidative stress. Hypoxia may cause a loss of balance between oxidant and anti-oxidant levels and lead to lung inflammation [39]. Yue et al demonstrated that prophylactic administration of ethanolic extract of PO decreased the vascular permeability and prevented the NF-KB up-regulation following hypoxia-induced pulmonary edema in the mouse. Furthermore, ethanolic extract of PO alleviated the levels of pro-inflammatory cytokines (IL- $1 \beta$ and TNF- $\alpha$ ) and cell adhesion molecules (ICAM1, VCAM-1 and P-selectin) in the lungs of mice in comparison to the hypoxia group. They suggested that ethanol extract of $\mathrm{PO}$ has effective and protective activities against pulmonary edema and hypoxia in the lung of mice [12].

Purslane has a water-soluble polysaccharide which is called CPOP (crude PO polysaccharide). In recent years, several studies have reported that cytokine-mediated inflammation is responsible for the pathogenesis of type II diabetes mellitus. Some inflammatory cytokines including TNF- $\alpha$ and IL- 6 have involved in the causality of insulin resistance and increase the risk of microvascular dysfunction in type II diabetes. CPOP significantly decreased TNF- $\alpha$ and IL-6 level in diabetic rats as well as SOD and MDA. These results indicate that the anti-diabetic effect of CPOP may be related to anti-oxidant and anti-inflammatory effects [6]. Furthermore, it has been revealed that omega-3 fatty acids in PO leave possess strong anti-inflammatory properties [40]. All anti-inflammatory effects of PO are summarized in Table 1.

\subsection{Anti-oxidant Activity}

There are many studies indicating the protective effects of PO could be through its anti-oxidant activity (Table 2). Proline and betalain pigments which are produced in Purslane showed anti-oxidant properties and protect the plant against saline stress [41]. PO is the main source of anti-oxidant vitamins such as $\alpha$-tocopherol, ascorbic acid, $\beta$-carotene and glutathione. Dkhil et al evaluated the anti-oxidative effects of PO aqueous juice in adult male Waster albino rats. The results revealed that oral administration of PO juice reduced the liver function tests (ALT, AST, $\gamma$-GT and ALP) and kidney function tests (the levels of urea, serum creatinine and blood urea nitrogen). Moreover, PO juice augmented the levels of superoxide dismutase (SOD), catalase (CAT), glutathione peroxidase (GPx), glutathione-S-transferase (GST), glutathione reductase (GR), glutathione (GSH) as well as diminished MDA and NO in liver, kidney and testis of rats [11].

Aging is associated with a progressive reduction in immune activity or immunosenescence. In fact, aging is the result of endogenous oxygen radical accumulation that is produced by oxidative changes of biomolecules [42]. Ahangarpour et al appraised the effect of PO on the reproductive system of D-galactose aged female mice. They reported that D-galactose significantly enhanced the LH and FSH level and MDA content, decreased estrogen and progesterone level as well as SOD and CAT activities. PO markedly reversed these changes and improved aging induced by D-galactose [42].

Gai et al showed that purslane seed oil (PSO) exhibits a significant dose-dependent in-vitro anti-oxidant activity and inhibits the oxidation of horse oil lipids during storage. Moreover, PSO notably prevented tumor cell growth in cervical cancer HeLa cells, esophageal cancer Eca-109

Table 2 Summary of the anti-oxidant effects of Portulaca oleracea.

\begin{tabular}{|c|c|c|c|}
\hline $\begin{array}{c}\text { Type of extract or } \\
\text { constituents }\end{array}$ & Study model & Result & Ref. \\
\hline $\begin{array}{l}\text { Proline and betalain pigments } \\
\text { found in PO }\end{array}$ & Saline-induced stress in plant & Showed anti-oxidant properties and protect the plant. & 41 \\
\hline PO aqueous juice & adult male Waster albino rats & $\begin{array}{l}\text { Reduced the liver function tests (ALT, AST, } \gamma \text {-GT, } \\
\text { and ALP) and kidney function tests (the levels of } \\
\text { urea, serum creatinine, and blood urea nitrogen). } \\
\text { Augmented the levels of SOD, CAT, GPx, GST, GR, } \\
\text { GSH as well as diminished MDA and NO in liver, } \\
\text { kidney, and testis of rats. }\end{array}$ & 11 \\
\hline PO ethanolic extract & $\begin{array}{l}\text { D-galactose induced aging in } \\
\text { female mice }\end{array}$ & $\begin{array}{l}\text { Decreased the LH and FSH level and MDA content. } \\
\text { Increased estrogen and progesterone levels as well as } \\
\text { SOD and CAT activities. }\end{array}$ & 42 \\
\hline Purslane seed oil & $\begin{array}{l}\text { Horse oil lipids and HeLa, Eca- } \\
109 \text { and MCF-7 cells }\end{array}$ & $\begin{array}{l}\text { In-vitro anti-oxidant activity. } \\
\text { Inhibits the oxidation of horse oil lipids during } \\
\text { storage. } \\
\text { Prevented tumor cell growth in HeLa, Eca-109 and } \\
\text { MCF-7 cells. }\end{array}$ & 13 \\
\hline СРОР & $\begin{array}{l}\text { Streptozotocin-induced } \\
\text { diabetes in the rat }\end{array}$ & $\begin{array}{l}\text { Reduced the MDA and SOD activities in the liver } \\
\text { tissue }\end{array}$ & 6 \\
\hline $\begin{array}{l}70 \% \text { hydro-ethanolic PO } \\
\text { extract and ALA }\end{array}$ & $\begin{array}{c}\mathrm{OVA}+\mathrm{Al}(\mathrm{OH}) 3 \text {-induced } \\
\text { asthma in rats }\end{array}$ & $\begin{array}{l}\text { Mitigated the } \mathrm{NO}_{2}, \mathrm{NO}_{3} \text {, and MDA, serum levels, } \\
\text { total WBC number and percentage of eosinophils and } \\
\text { neutrophils. } \\
\text { Propagated SOD, CAT and thiol levels. }\end{array}$ & 43 \\
\hline $\begin{array}{c}\text { aqueous and ethanolic extract } \\
\text { of PO }\end{array}$ & $\begin{array}{c}\mathrm{H}_{2} \mathrm{O}_{2} \text { - induced DNA damage in } \\
\text { human lymphocytes }\end{array}$ & $\begin{array}{l}\text { Aqueous extract of PO inhibited DNA damage by } \\
\text { comet assay, while this effect was not present in its } \\
\text { ethanolic extract. }\end{array}$ & 44 \\
\hline
\end{tabular}


cells and breast cancer MCF-7 cells [13]. Several studies reported a positive correlation between the antioxidant activity in plants and the total content of phenolic compounds [10]. Pieces of evidence suggest that active oxygen species play a role in the pathogenesis of diabetes and its complications. There is a direct correlation between oxidative stress and diabetes. SOD, as an intrinsic anti-oxidant, reduces the toxic effects of oxygen radicals. MDA is a sensitive indicator of the metabolic rate of free radicals. CPOP reduced the MDA and SOD activities in the liver tissue of streptozotocin-induced diabetic rats. Therefore, the anti-diabetic effect of CPOP is associated with its anti-oxidant effect [6].

Kaveh et al measured the effects of $70 \%$ hydro-ethanolic PO extract (1, 2 and $4 \mathrm{mg} / \mathrm{mL})$ and alpha-linolenic acid (ALA, 0.2 and $0.4 \mathrm{mg} / \mathrm{mL}$ ), as one of the main constituents of PO, on serum oxidant levels and inflammatory cells in ovalbumin (OVA)+Al(OH)3 -induced asthma in rats. The results of this study revealed that PO extract and ALA reduce the $\mathrm{NO}_{2}, \mathrm{NO}_{3}$ and MDA, serum levels, total WBC number and percentages of eosinophil and neutrophil. Furthermore, it propagated SOD, CAT and thiol levels following OVA+ $\mathrm{Al}(\mathrm{OH}) 3$-induced asthma. The anti- oxidative and anti-inflammatory effects of PO and ALA were comparable with dexamethasone $(1.25 \mu \mathrm{g} / \mathrm{mL})$ [43].

Behravan et al figured out the effects of aqueous and ethanolic extract of $\mathrm{PO}$ on $\mathrm{H}_{2} \mathrm{O}_{2}$ - induced DNA damage in human lymphocytes. The results of this study demonstrated that aqueous extract of PO significantly inhibited DNA damage by comet assay, while this effect was not present in its ethanolic extract. They suggested that PO aqueous extract could prevent oxidative DNA damage to human lymphocytes probably because of the anti-oxidant components contained in the PO [44].

\subsection{Immuno-modulatory Activity}

There are several studies notion the immuno-modulatory properties of $\mathrm{PO}$ which summarized in Table 3 . In this context, Costa et al demonstrated that ethyl acetate and chloroform extracts of Portulaca werdermannii and Portulaca hirsutissima encompass potent immuno-modulatory activities. They showed that all four tested extracts inhibited the proliferation induced by concanavalin A (Con A) in BALB/c-isolated splenocytes [1].

Recently, Askari et al. evaluated the effects of PO hydro-ethanolic extract $\mathrm{Th}_{1} / \mathrm{Th}_{2}$ balance on the isolated human lymphocytes. As results, PO (160, 40 and $10 \mu \mathrm{g} / \mathrm{ml})$ meaningfully alleviates the percentage of cell proliferation, NO production and cytokines (IL-4, IL10 and IFN- $\gamma$ ) secretion in PHA-stimulated lymphocytes. Moreover, $\mathrm{Th}_{1} /$ $\mathrm{Th}_{2}$ (IFN- $\left.\gamma / \mathrm{IL}-4\right)$ and $\mathrm{T}_{\mathrm{reg}} / \mathrm{Th}_{2}$ (IL-10/IL-4) balances were propagates following PHA-induced stimulation in human isolated lymphocytes. These data emphasized the anti-inflammatory properties of PO [2].

Georgiev et al showed that polysaccharide complexes (PSCs) isolated from the aerial parts of PO possess immunomodulatory properties on human white blood cells. These polysaccharides stimulated $\mathrm{CD} 4^{+}$cells, while they did not induce $\mathrm{CD} 20^{+}$cells that represent the population of B cells. Furthermore, they activated the CD25+ cells that are related to both $\mathrm{B}$ and T cells. $\mathrm{PO}$ polysaccharides exhibited activity on $\mathrm{CD} 4^{+} / \mathrm{CD}^{2} 5^{+}$and $\mathrm{CD}^{+} / \mathrm{CD}^{+} 5^{+} \mathrm{T}$ cells that are responsible for regulating the immune response in autoimmune and tumorigenic diseases. In addition, they activated phagocytes that are involved in the first mechanism of innate defense and the process of inflammation and, as a result, stimulate the activity of the immune system. Moreover, PO polysaccharides express

Table 3 Summary of the immuno-modulatory effects of Portulaca oleracea.

\begin{tabular}{|c|c|c|c|}
\hline Type of extract or constituents & Study model & Result & Ref. \\
\hline $\begin{array}{l}\text { ethyl acetate and chloroform } \\
\text { extracts of Portulaca } \\
\text { werdermannii and Portulaca } \\
\text { hirsutissima }\end{array}$ & BALB/c-isolated splenocytes & $\begin{array}{c}\text { Inhibited the proliferation induced by concanavalin A } \\
\text { in BALB/c-isolated splenocytes }\end{array}$ & 1 \\
\hline PO hydro-ethanolic extract & $\begin{array}{l}\text { PHA-stimulated human } \\
\text { lymphocytes }\end{array}$ & $\begin{array}{l}\text { Attenuated the percentage of cell proliferation, NO } \\
\text { production and the levels of IL-4, IL10, and IFN- } \gamma \text {. } \\
\text { Propagates the Th1/Th2 (IFN- } \gamma / \text { IL-4) and Treg/Th2 } \\
\text { (IL-10/IL-4) balances. }\end{array}$ & 2 \\
\hline $\begin{array}{l}\text { polysaccharide complexes } \\
\text { (PSCs) isolated from aerial } \\
\text { parts of PO }\end{array}$ & $\begin{array}{l}\text { Human white blood cells } \\
\text { Peyer's patch (PP) cells from } \\
\text { the small intestine of mice }\end{array}$ & $\begin{array}{c}\text { Stimulated CD } 4^{+}, \mathrm{CD} 25^{+} \text {cells. } \\
\text { Activated phagocytes } \\
\text { Enhanced IL-6 produced from white blood cells. } \\
\text { Intestinal immuno-modulatory activities by } \\
\text { interacting with immune cells in Peyer's patch cells. }\end{array}$ & 36 \\
\hline Purslane polysaccharides (PPs) & $\begin{array}{l}\text { MNNG -induced gastric } \\
\text { cancer in rats }\end{array}$ & $\begin{array}{c}\text { Appended SOD, CAT, GSH-Px, IL-2, IL-4 and TNF- } \\
\alpha \text { levels. } \\
\text { Raised the body weight, lymphocyte proliferation, } \\
\text { WBC count and splenocytes proliferation. }\end{array}$ & 45 \\
\hline $\begin{array}{c}\text { 70\% hydro-ethanolic PO } \\
\text { extract }\end{array}$ & Asthmatic rats & $\begin{array}{c}\text { Attenuates the levels of total protein, PLA2, and IgE } \\
\text { in BALF }\end{array}$ & 46 \\
\hline $\begin{array}{l}\text { Pumpkin/purslane seed } \\
\text { mixture }\end{array}$ & Hyper-cholesterolemic rats & $\begin{array}{l}\text { Mitigates the lipid parameters. } \\
\text { Improves IgG and IgM levels. }\end{array}$ & 47 \\
\hline PO ethyl acetate extract & $\begin{array}{l}\text { Cyclophosphamide-induced } \\
\text { immuno-suppression in mice }\end{array}$ & $\begin{array}{l}\text { Elevated phagocytosis and higher proliferative } \\
\text { response in splenic lymphocytes. }\end{array}$ & 48 \\
\hline
\end{tabular}


activity on $\mathrm{CD} 14^{+}$cells or monocytes as well as enhanced IL-6 produced from white blood cells. CD14 proteins inherent in the immune response are expressed in phagocytes, while $\mathrm{CD}^{+}$and $\mathrm{CD}^{+}$are mainly related to T-cells and immune-compatibility. They have a positive effect on the immune system and have a negative effect on inflammation. PO polysaccharide compounds also have an immuno-modulatory activity on the gastrointestinal tract. They showed intestinal immuno-modulatory activity by interacting with immune cells in Peyer's patch (PP) cells from the small intestine of mice. Although the polysaccharides are slightly absorbed, their connection with epithelium could lead to immuno-modulation of the underlying immuno-competent cells [36].

Li et al evaluated the anti-oxidant and immuno-enhancing activities of Purslane polysaccharides (PPs) following N-methyl-N-nitro-N-nitrosoguanidine (MNNG) -induced gastric cancer in rats. The results of this study revealed that PPs markedly protect against oxidative stress induced by MNNG through appended SOD, CAT and GSH-Px level in gastric cancer rats. Furthermore, PPs treatment significantly raised the body weight, lymphocyte proliferation, WBC count and splenocytes proliferation of gastric cancer rats. Moreover, the release of serum cytokines such as IL2 , IL-4 and TNF- $\alpha$ were raised in gastric cancer rats following PPs treatment. .It is concluded that the PPs execute its anti-tumor activity through improving immunologic function and oxidative status of gastric cancer rats [45].

Boskabady et al evaluated the anti-inflammatory and immuno-modulatory effects of $\mathrm{PO}$ in asthmatic rats. The results revealed that PO notably and dose-dependently attenuates the levels of total protein (TP), phospholipase A2 (PLA2) and IgE in broncho-alveolar lavage fluid (BALF) of asthmatic rats. Moreover, the anti-inflammatory and immuno-modulatory effects of $\mathrm{PO}$ were equal or stronger than dexamethasone treatment [46]. In another study, it has been suggested that pumpkin/purslane seed mixture markedly mitigates the lipid parameters as well as improves IgG and IgM levels in hypercholesterolemic rats which represents the anti-atherogenic and immunomodulatory properties of $\mathrm{PO}$ [47].
Catap et al measured the immuno-modulatory effects of PO ethyl acetate (EA) extract on cyclophosphamide-induced immuno-suppression in mice. The results supported that EA extract of PO possesses immuno-activity through elevated phagocytosis and higher proliferative response in splenic lymphocytes which emphasized the immuno-modulatory properties of PO [48].

\subsection{Antitumor Activity}

Previous studies showed that traditional medicine could be a promising source of potential anti-cancer drug therapy (Table 4). Some of the compounds found in PO including omega-3 fatty acids and in particularly ALA are considered as tumor suppressants [41]. It has been demonstrated that PO polysaccharides bear anti-tumor activities through strengthening the immune system [36]. In addition, polysaccharides also have anti-viral and analgesic activities [41]. Shen et al proved that PO polysaccharides inhibit the tumor growth in animal models and increase animal immunity. Treatment with these polysaccharides enhanced the amount of $\mathrm{CD} 4^{+} \mathrm{T}$ lymphocytes, WBC numbers and the ratio of $\mathrm{CD}^{+} / \mathrm{CD}^{+}$in the peripheral blood of transplantable sarcoma 180 mice. Furthermore, PO polysaccharides decreased the tumor growth, AST, ALT, BUN and creatinine levels in S180-bearing mice. Therefore, it can be concluded that the anti-tumor effect of PO polysaccharides is related to its immuno-stimulating activities [49].

Farshori et al figured out the anti-cancer properties of PO seed extract on the human hepatocellular carcinoma cells (HepG2). The results of this study revealed that PO remarkably mitigates the HepG2 cell viability in a dose-dependent manner. Furthermore, PO seed extract diminished the typical morphology and adhesion capacity of HepG2 cells. It is concluded that PO possesses anti-cancer properties in HepG2 cells [50].

It has been emphasized that PO polysaccharides notably scavenge superoxide anion, 1, 1-diphenyl-2-picrylhydrazyl (DPPH (-)), NO and hydroxyl radicals. Moreover, PO polysaccharides prevented the red blood cell (RBC)

Table 4 Summary of the anti-tumor effects of Portulaca oleracea.

\begin{tabular}{|c|c|c|c|}
\hline Type of extract or constituents & Study model & Result & Ref. \\
\hline PO polysaccharides & $\begin{array}{c}\text { Tumor-bearing sarcoma } 180 \\
\text { mouse }\end{array}$ & $\begin{array}{c}\text { Enhanced the amount of CD } 4^{+} \mathrm{T} \text { lymphocytes, WBC } \\
\text { numbers and the ratio of CD4 }(+) / \mathrm{CD} 8(+) . \\
\text { Decreased the tumor growth, AST, ALT, BUN, and } \\
\text { creatinine levels. }\end{array}$ & 49 \\
\hline PO seed extract & HepG2 cells & $\begin{array}{l}\text { Mitigates the HepG2 cell viability, typical } \\
\text { morphology and adhesion capacity of HepG2 cells. }\end{array}$ & 50 \\
\hline PO polysaccharides & Rats with ovarian cancer & $\begin{array}{c}\text { Scavenge DPPH, NO and hydroxyl radicals. } \\
\text { Prevented the RBC hemolysis as well as propagated } \\
\text { the spleen, thymocyte T and B lymphocyte } \\
\text { proliferation. }\end{array}$ & 51 \\
\hline $\begin{array}{c}\text { Sulfated derivatives of PO } \\
\text { polysaccharide }\end{array}$ & $\begin{array}{c}\text { HepG2 and HeLa cancer cell } \\
\text { lines }\end{array}$ & Suppressed the growth of HeLa and HepG 2 cells. & 52 \\
\hline Portulacerebroside A (PCA) & $\begin{array}{l}\text { Human liver cancer } \\
\text { HCCLM3 cells }\end{array}$ & $\begin{array}{l}\text { Reduces the viability. } \\
\text { Elevated the percentage of apoptotic cells, the } \\
\text { phosphorylation of p38 MAPK and JNK, the release } \\
\text { of mitochondrial cytochrome c and AIF to the cytosol } \\
\text { as well as activation of caspase- } 9 \text { and caspase-3. }\end{array}$ & 53 \\
\hline
\end{tabular}


hemolysis as well as propagated the spleen, thymocyte $\mathrm{T}$ and $\mathrm{B}$ lymphocyte proliferation isolated from rats with ovarian cancer [51]. Chen et al evaluated the cytotoxicity effects of sulfated derivatives of PO polysaccharide (POP) on liver (HepG2) and cervical (HeLa) cancer cell lines. The results showed that POP sulfated derivatives suppressed the growth of HeLa and HepG2 cells. It could be concluded that the sulfating of POP raises its toxicity for tumor cells [52].

It has been also demonstrated that other bioactive compounds in PO including alkaloids, homoisoflavonoids and cerebrosides possess in-vitro cytotoxic effects against human cancer cell lines. Zheng et al suggested that Portulacerebroside A (PCA), a novel cerebroside compound isolated from $\mathrm{PO}$, reduces the viability of human liver cancer HCCLM3 cells. Additionally, PCA markedly elevated the percentage of apoptotic cells, the phosphorylation of p38 MAPK and JNK, the release of mitochondrial cytochrome $\mathrm{c}$ and AIF to the cytosol as well as activation of caspase-9 and caspase-3 [53]. These studies emphasized that PO could be a good candidate for cancer treatment.

\section{Conclusion}

The results indicated that PO significantly inhibits the tumor cell growth in a time- and dose- dependent manner. Additionally, these studies suggest that PO may exert its effects through anti- inflammatory properties and balancing the adaptive and innate immune system depending on situations. As mentioned previously, PO can inhibit the inflammatory states by the dominance of Th2 response such as asthma, cancer and atopic dermatitis and modulate this imbalance toward Thl response. In contrast, the results showed that PO modulates the evoked Th1 disorders including hepatitis and multiple sclerosis. Taken together, PO is known as immuno-modulatory and anti-oxidant medicinal herb, which may be introduced for the treatment of many immunological based disorders. In addition, it could be used as a substitute for synthetic anti- oxidant in food preservation and may be potentially useful as a food and cosmetic ingredient. Meanwhile, the oxidative stress can cause hyper-sensitivities, so PSO is expected to develop a health care product for the prevention and mitigation of hyper-sensitivities symptoms. PSO is expected to show superior anti-oxidant activity and anti-tumor effects due to its high omega-3 fatty acid content. Thus, it is a good candidate as both a healthy food and cosmetic ingredient.

\section{References}

1. Costa JFO, Kiperstok AC, de Lima David JP, David JM, Giulietti AM, de Queiroz LP, et al. Anti-leishmanial and immunomodulatory activities of extracts from Portulaca hirsutissima and Portulaca werdermannii. Fitoterapia. 2007;78(7):510-4.

2. Askari VR, Rezaee SA, Abnous K, Iranshahi M, Boskabady MH. The influence of hydro- ethanolic extract of Portulaca oleracea L. on Th1/Th2 balance in isolated human lymphocytes. J. Ethnopharmacol. 2016;194:1112-21.

3. Noorbakhshnia M, Karimi-Zandi L. Portulaca oleracea L. prevents lipopolysaccharide-induced passive avoidance learning and memory and TNF- $\triangle$ impairments in hippocampus of rat. Physiol. Behav. 2017;169:69-73.

4. Iranshahy M, Javadi B, Iranshahi M, Jahanbakhsh SP, Mahyari S, Hassani FV, et al. A review of traditional uses, phytochemistry, and pharmacology of Portulaca oleracea L. J. Ethnopharmacol. 2017;205:158-72.

5. Wu B, Yu L, Wu X, Chen J. New CuCl 2-induced glucoside esters and other constituents from Portucala oleracea. Carbohydr. Res. 2012;351:68-73.

6. Bai Y, Zang X, Ma J, Xu G. Anti-diabetic effect of Portulaca oleracea L. Polysaccharideandits mechanism in diabetic rats. Int. J. Mol. Sci. 2016;17(8):1201.

7. Lee AS, Kim JS, Lee YJ, Kang DG, Lee HS. Anti-TNF-alpha activity of Portulaca oleracea in vascular endothelial cells. Int. J. Mol. Sci. 2012;13(5):5628-44.

8. Chan K, Islam M, Kamil M, Radhakrishnan R, Zakaria M, Habibullah M, et al. The analgesic and anti-inflammatory effects of Portulaca oleracea L. subsp. sativa (Haw.) Celak. J. Ethnopharmacol. 2000;73(3):445-51.

9. Shakeri F, Boskabady $\mathrm{MH}$. A review of the relaxant effect of various medicinal plants on tracheal smooth muscle, their possible mechanism (s) and potency. J. Ethnopharmacol. 2015;175:528-48.

10. Lim Y, Quah E. Antioxidant properties of different cultivars of Portulaca oleracea. Food Chem. 2007;103(3):734-40.

11. Dkhil MA, Moniem AEA, Al-Quraishy S, Saleh RA. Antioxidant effect of purslane (Portulaca oleracea) and its mechanism of action. J. Med. Plant. Res. 2011;5(9):158993.

12. Yue T, Xiaosa W, Ruirui Q, Wencai S, Hailiang X, Min L. The Effects of Portulaca oleracea on Hypoxia-Induced Pulmonary Edema in Mice. High Alt. Med. Biol. 2015;16(1):43-51.

13. Gai Guo LY, Fan S, Jing S, Yan L-J. Antioxidant and Antiproliferative Activities of Purslane Seed Oil. J. Hypertens. 2016;5(2).

14. Li L-L, Wang N, Zhang Y-H, Li Y-X, Chen X, editors. Effect of Extraction Reagents on the Content of Phenolics and Antioxidant Activity of Portulaca oleracea L. XXVII International Horticultural Congress-IHC2006: International Symposium on Plants as Food and Medicine: The Utilization 765; 2006.

15. Zhou Y-X, Xin H-L, Rahman K, Wang S-J, Peng C, Zhang H. Portulaca oleracea L.: a review of phytochemistry and pharmacological effects. BioMed Res. Int. 2015; 2015. 
16. $\mathrm{Xu} \mathrm{X}, \mathrm{Yu} \mathrm{L}$, Chen G. Determination of flavonoids in Portulaca oleracea L. by capillary electrophoresis with electrochemical detection. J. Pharm. Biomed. Anal. 2006;41(2):493-9.

17. Zhu H, Wang Y, Liu Y, Xia Y, Tang T. Analysis of Flavonoids in Portulaca oleracea L. by UV- Vis Spectrophotometry with Comparative Study on Different Extraction Technologies. Food Anal. Methods. 2010;3(2):90-7.

18. Yan J, Sun LR, Zhou ZY, Chen YC, Zhang WM, Dai HF, et al. Homoisoflavonoids from the medicinal plant Portulaca oleracea. Phytochemistry. 2012;80:37-41.

19. Yue ME, Jiang TF, Shi YP. Simultaneous determination of noradrenaline and dopamine in Portulaca oleracea L. by capillary zone electrophoresis. J. Sep. Sci. 2005;28(4):360-4.

20. Chen J, Shi YP, Liu JY. Determination of noradrenaline and dopamine in Chinese herbal extracts from Portulaca oleracea L. by high-performance liquid chromatography. J. Chromatogr. A. 2003;1003(1- 2):127-32.

21. Xiang L, Xing D, Wang W, Wang R, Ding Y, Du L. Alkaloids from Portulaca oleracea L. Phytochemistry. 2005;66(21):2595-601.

22. Tian JL, Liang X, Gao PY, Li DQ, Sun Q, Li LZ, et al. Two new alkaloids from Portulaca oleracea and their cytotoxic activities. J. Asian Nat. Prod. Res. 2014;16(3):259-64.

23. Liang X, Tian J, Li L, Gao J, Zhang Q, Gao P, et al. Rapid determination of eight bioactive alkaloids in Portulaca oleracea L. by the optimal microwave extraction combined with positive-negative conversion multiple reaction monitor (+/-MRM) technology. Talanta. 2014;120:167-72.

24. Aljeboori KH, Rubai O, Nahi O, Yassen N. Study of pathological, effects of crude extract of Portulaca olercea L. in the albino mice organs. Int. J. Tech. Res. Appl. 2014;2(1):29-32.

25. Sakai N, Inada K, Okamoto M, Shizuri Y, Fukuyama Y. Portuloside A, a monoterpene glucoside, from Portulaca oleracea. Phytochemistry. 1996;42(6):1625-8.

26. Seo Y-W, Shin J-H, Cha H-J, Kim Y-A, Ahn J-W, Lee B-J, et al. A new monoterpene glucoside from Portulaca oleracea. Bull. Korean Chem. Soc. 2003;24(10):1475-7.

27. Elkhayat ES, Ibrahim SR, Aziz MA. Portulene, a new diterpene from Portulaca oleracea L. J. Asian Nat. Prod. Res. 2008;10(11-12):1039-43.

28. Xin H-L, Xu Y-F, Hou Y-H, Zhang Y-N, Yue X-Q, Lu J-C, et al. Two Novel Triterpenoids from Portulaca oleracea L. Helv. Chim. Acta. 2008;91(11):2075-80.

29. Mohamed AI, Hussein AS. Chemical composition of purslane (Portulaca oleracea). Plant Foods Hum. Nutr. 1994;45(1):1-9.

30. Uddin MK, Juraimi AS, Hossain MS, Nahar MA, Ali ME, Rahman MM. Purslane weed (Portulaca oleracea): a prospective plant source of nutrition, omega-3 fatty acid, and antioxidant attributes. ScientificWorldJournal. 2014;2014:951019.

31. Cheng Z, Wang D, Zhang W, Du Y, Wang Y, Zhai Y, et al. LC determination and pharmacokinetic study of the main phenolic components of Portulaca oleracea L. extract in rat plasma after oral administration. Nat. Prod. Res. 2012;26(23):2247-50.

32. Palaniswamy UR, McAvoy RJ, Bible BB. Stage of harvest and polyunsaturated essential fatty acid concentrations in purslane (Portulaca oleraceae) leaves. J. Agric. Food Chem. 2001;49(7):3490-3.

33. Esiyok D, Otles S, Akcicek E. Herbs as a food source in Turkey. Asian Pac. J. Cancer Prev. 2004;5(3):334-9.

34. Simopoulos AP, Tan DX, Manchester LC, Reiter RJ. Purslane: a plant source of omega- 3 fatty acids and melatonin. J. Pineal Res. 2005;39(3):331-2.

35. Palaniswamy UR, Bible BB, McAvoy RJ. Effect of nitrate: ammonium nitrogen ratio on oxalate levels of purslane. Trends New Crops New Uses. 2002;11(5):453-5.

36. Georgiev YN, Ognyanov MH, Kiyohara H, Batsalova TG, Dzhambazov BM, Ciz M, et al. Acidic polysaccharide complexes from purslane, silver linden and lavender stimulate Peyer's patch immune cells through innate and adaptive mechanisms. Int. J. Biol. Macromol; 2017.

37. Xu L, Ying Z, Wei W, Hao D, Wang H, Zhang W, et al. A novel alkaloid from Portulaca oleracea L. Nat. Prod. Res. 2017;31(8):902-8.

38. Kim CH, Park PB, Choe SR, Kimz TH, Lee JKJKG LC. Anti-oxidative and Anti-inflammatory Effects of Portulaca oleracea on the LPS-stimulated AGS Cells. Korean J. Orient. Physiol. Pathol. 2009;23(2):I488-93.

39. Swamy M, Salleh MJM, Sirajudeen K, Yusof WRW, Chandran G. Nitric oxide (no), citrulline-no cycle enzymes, glutamine synthetase and oxidative stress in anoxia (hypobaric hypoxia) and reperfusion in rat brain. Int. J. Med. Sci. 2010;7(3):147.

40. Malek F, Boskabady M, Borushaki M, Tohidi M. Bronchodilatory effect of Portulaca oleracea in airways of asthmatic patients. J. Ethnopharmacol. 2004;93(1):57-62.

41. Mulry KR, Hanson BA, Dudle DA. Alternative Strategies in Response to Saline Stress in Two Varieties of Portulaca oleracea (Purslane). PloS one. 2015;10(9):e0138723.

42. Ahangarpour A, Lamoochi Z, Moghaddam HF, Mansouri SMT. Effects of Portulaca oleracea ethanolic extract on reproductive system of aging female mice. Int. J. Reprod. BioMed. 2016;14(3):205.

43. Kaveh M, Eidi A, Nemati A, Boskabady MH. The Extract of Portulaca oleracea and its Constituent, Alpha Linolenic Acid Affects Serum Oxidant Levels and Inflammatory Cells in Sensitized Rats. Iran. J. Allergy. Asthma Immunol; 2017.

44. Behravan J, Mosafa F, Soudmand N, Taghiabadi E, Razavi BM, Karimi G. Protective effects of aqueous and ethanolic extracts of Portulaca oleracea L. aerial parts on $\mathrm{H}$ 20 2-induced DNA damage in lymphocytes by comet assay. J. Acupunct. Meridian Stud. 2011;4(3):193-7.

45. Li Y, Hu Y, Shi S, Jiang L. Evaluation of antioxidant and immuno-enhancing activities of Purslane polysaccharides in gastric cancer rats. Int. J. Biol. Macromol. 2014;68:113-6.

46. Kaveh M, Eidi A, Nemati A, Boskabady MH. Modulation of lung inflammation and immune markers in asthmatic rats treated by Portulaca oleracea. Avicenna J. Phytomed. 2017;7(5):409-16.

47. Barakat LA, Mahmoud RH. The antiatherogenic, renal protective and immunomodulatory effects of purslane, pumpkin and flax seeds on hypercholesterolemic rats. N. Am. J. Med. Sci. 2011;3(9):411-7.

48. Catap ES, Kho MJL, Jimenez MRR. In vivo nonspecif- 
ic immunomodulatory and antispasmodic effects of common purslane (Portulaca oleracea Linn.) leaf extracts in ICR mice. J. Ethnopharmacol. 2018;215:191-8.

49. Shen H, Tang G, Zeng G, Yang Y, Cai X, Li D, et al. Purification and characterization of an antitumor polysaccharide from Portulaca oleracea L. Carbohyd. Polym. 2013;93(2):395-400.

50. Farshori NN, Al-Sheddi ES, Al-Oqail MM, Musarrat J, AlKhedhairy AA, Siddiqui MA. Cytotoxicity Assessments of Portulaca oleracea and Petroselinum sativum Seed Extracts on Human Hepatocellular Carcinoma Cells (HepG2). Asian Pac. J. Cancer Prev. 2014;15(16):6633-8.

51. YouGuo C, ZongJi S, XiaoPing C. Evaluation of free radicals scavenging and immunity- modulatory activities of Purslane polysaccharides. Int. J. Biol. Macromol. 2009;45(5):448-52.

52. Chen T, Wang J, Li Y, Shen J, Zhao T, Zhang H. Sulfated modification and cytotoxicity of Portulaca oleracea L. polysaccharides. Glycoconj J. 2010;27(6):635-42.

53. Zheng G-Y, Qu L-P, Yue X-Q, Gu W, Zhang H, Xin H-L. Portulacerebroside A induces apoptosis via activation of the mitochondrial death pathway in human liver cancer HCCLM3 cells. Phytochem. Lett. 2014;7:77-84. 